\title{
HLA class I haplotypes and progression of primary open-angle glaucoma
}

\author{
Haplotipos HLA de classe I e progressão do glaucoma primário de ângulo aberto
}

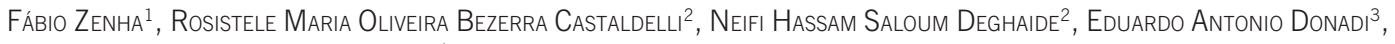
Maria de Lourdes Veronese Rodrigues ${ }^{1}$

\begin{abstract}
Purpose: To verify if patients with primary open-angle glaucoma with HLA class I haplotypes (A9-B12, A2-B40, A1-B8) associated with this disease may have a greater rate of progression than patients who do not present these haplotypes.

Methods: Anatomical and functional glaucoma evaluation (cup-to-disc ratio and visual field) of 25 patients (six of them with one of the haplotypes associated with glaucoma) followed at the Glaucoma Outpatient Clinic of the University Hospital, Ribeirão Preto School of Medicine, São Paulo University (HCFMRP-USP) for ten years after typing of their HLA antigens in order to compare with their previous condition. Results: A greater increase of the cup-to-disc ratio was observed in patients with HLA haplotypes associated with primary open-angle glaucoma predisposition. However, no significant differences in functional damage progression or in retinal nerve fibers loss were detected between them and other patients with glaucoma.

Conclusion: The present results indicate an association of class I HLA haplotypes with progression of anatomic alterations of the optic nerve head in glaucomatous patients.
\end{abstract}

Keywords: Glaucoma, open-angle; HLA antigens; Visual fields; Haplotypes

\section{RESUMO}

Objetivo: Verificar se pacientes com glaucoma primário de ângulo aberto portadores de haplotipos HLA de classe I (HLA - A9-B12; -A2-B40; e -A1-B8) associados a essa doença poderiam ter progressão maior do que pacientes que não apresentassem esses haplotipos

Método: Avaliação anatômica e funcional de 25 pacientes ( 6 dos quais com um dos haplotipos associados a glaucoma), seguidos no Ambulatório de Glaucoma do Hospital das Clínicas da Faculdade de Medicina de Ribeirão Preto da Universidade de São Paulo (HCFMRP-USP), por dez anos depois da tipificação de seus antígenos HLA, para comparação com as condições anteriores.

Resultados: Houve aumento maior da relação escavação/disco em pacientes com haplotipos HLA associados com predisposição para glaucoma primário de ângulo aberto, no entanto não foram encontradas diferenças significantes entre esses $e$ outros pacientes com glaucoma na progressão do dano fisiológico e nem na perda de fibras nervosas da retina.

Conclusão: Os resultados indicam a associação de haplotipos HLA de classe I com maior taxa de progressão das alterações anatômicas da cabeça nervo óptico em pacientes com glaucoma.

Descritores: Glaucoma de ângulo aberto; Antígenos HLA; Campos visuais; Haplotipos

\section{INTRODUCTION}

Considering the hypothesis that may exist a relation between the loci of the HLA specificities and the loci of substances related to the genesis of glaucoma ${ }^{(1-2)}$, several investigators have tried to correlate HLA complex antigens with primary open-angle glaucoma (POAG). Nevertheless, no fully concordant data have been obtained thus far, since different antigens have been associated with glaucoma.

Association of POAG with HLA B12 and HLA B7(3) or only with HLA B12 $2^{(4)}$ has been detected, as well as an association of HLA B35 as a risk factor for susceptibility to POAG(5). Other studies have identified class II HLA antigens such as HLA-DR3 in a mexican family ${ }^{(6)}$ and HLA DQ I and HLA DR II in Italians ${ }^{(7)}$.

The results of a study conducted in Brazil(8) has suggested a possible association of POAG with the HLA system. Despite the fact that this study showed that there was no association of simple chronic glaucoma with any $A$ or $B$ HLA antigen alone, the results suggested an association with the HLA A9-B12, A2-B40 and A1-B8 haplotypes and this disease.
The objectives of the present study were: a) to determine if a greater anatomical progression in cup-to-disc ratio damage occurred over a period of ten years in patients with class I HLA haplotypes associated with predisposition to POAG than in patients without these haplotypes; and b) if these eventual differences were associated with differences in the progression of functional damage.

\section{METHODS}

The reference population consisted of 50 patients from the Glaucoma Outpatient Clinic of Medical School of Ribeirão Preto University Hospital, evaluated ten years ago. The inclusion criteria were presence of POAG under treatment and no history of systemic arterial hypertension, diabetes mellitus or Chagas' disease and neurological diseases.

The study population consisted of 25 (15 males) of the original patients who could be evaluated. The remaining 25 were not included for different reasons, such as severe diseases, death, drop-out of glaucoma treatment, and migrations.
Submitted for publication: August 4,2010

Accepted for publication: February 2, 2011

Study carried out at the Department of Ophthalmology, Otorhinolaringology and Head and Neck Surgery, Faculdade de Medicina de Ribeirão Preto, Universidade de São Paulo - USP - Brazil.

${ }^{1}$ Physician, Department of Ophthalmology, Otorhinolaringology and Head and Neck Surgery Ribeirão Preto School of Medicine, São Paulo University - USP - Ribeirão Preto (SP), Brazil.

2 Graduated Student, Program of Ophthalmology, Otorhinolaringology and Head and Neck Surgery,

Ribeirão Preto School of Medicine, São Paulo University - USP - Ribeirão Preto (SP), Brazil.

${ }_{3}^{3}$ Physician, Department of Internal Medicine/Immunology, Ribeirão Preto School of Medicine, São

Paulo University - USP - Ribeirão Preto (SP), Brazil.
Funding: This study was supported by CNPq (Conselho Nacional de Desenvolvimento Científico e Tecnológico, Brasília, DF, Brazil).

Disclosure of potential conflicts of interest: F.Zenha, None; R.M.O.B.Castaldelli, None; N.H.S. Deghaide, None; E.A.Donadi, None; M.L.V.Rodrigues, None.

Correspondence address: Profa . Dra. Maria de Lourdes Veronese Rodrigues. Hospital das Clínicas, Oftalmologia - Campus USP - Ribeirão Preto - SP - 14048-900 - Brazi

E-mail: mdlvrodr@fmrp.usp.br

Editorial Note: After completing the confidential analysis of the manuscript, ABO discloses, with

his agreement, the name Dr. Maurício Della Paolera as a reviewer. We thank his effort and expertise

in participating in this process. 
Ages ranged from 35 to 90 years (median: 65 years). According to skin color, 18 patients were characterized as Caucasians, 6 as afrodescendents and 1 as Oriental.

HLA class I antigens were typed using a microlymphocytotoxity assay $^{(8)}$.

Regarding the HLA profile, determined in the time of inclusion in the study, 6 patients were found to have one of the haplotypes described by Torres et al. ${ }^{(9)}$, a fact that led to the formation of two groups. Group A consisted of 6 patients presenting one of the A2B40 and A1-B8 HLA haplotypes and Group B consisted of the remaining 19 patients who did not present either haplotype.

The control population consisted of a group of 257 normal individuals who had donated kidneys at the São Paulo Interior Transplant (SPIT) Center.

At initial examination the visual acuity in the Group A subjects ranged from absence of light perception (ALP, 0 for statistical purposes) to 1 (median: 0.7). In the current exam, visual acuity ranged from ALP (0 for statistical purposes) to 0.8 (median: 0.3). For Group B, visual acuity ranged from ALP to 1 (median: 0.85) at initial examination and from ALP to 1 (median: 0.5) at current examination.

Patients were classified as having POAG according gonioscopy findings, intraocular pressure of $21 \mathrm{mmHg}$ or more, accompanied by changes suggestive of glaucoma in the head of the optic nerve and, or in the visual field.

Visual fields were classified according to the criteria of the Ocular Hypertension Treatment Study $(\mathrm{OHTS})^{(10)}$. In addition, perimetric losses were classified according to the following criteria:

1- Stable (no change in the visual field);

2- Mild (changes present also in another quadrant and/or increased lesions in the same quadrant);

3- Moderate (changes present in two more quadrants and/or marked increase of lesions in the same quadrant(s);

4- Severe (changes progressing to all quadrants or worsening of tubular loss).

Data from the patients' medical records were used to fill out cards which contained, in addition to data regarding the ophthalmologic exam, patient identification data and records of campimetric changes.

All the patients who returned for re-evaluation were submitted to anamnesis, measurement of visual acuity, tonometry, campimetry (at least two examinations), fundoscopy with retinography, and optical coherence tomography (OCT - Topcon ${ }^{\text {TM }}$, São Paulo, Brazil).

A classification was elaborated to assess the loss of nerve fibers by OCT using as reference the percentiles of normal distribution of the apparatus itself:

$1=p<1 \%$ - High involvement of nerve fibers

$2=1 \%<p<5 \%$ - Borderline involvement

$3=p>5 \%$ - Low involvement or normal condition
Data were analyzed statistically by the Fisher two-tailed exact test, with the level of significance set at $p \leq 0.05$ ( $95 \%$ confidence interval). When significant differences in frequency were detected between groups, the odds ratio (OR) was calculated, using statistical program Epilnfo 6.0.

\section{RESULTS}

HLA class I haplotypes associated with POAG in Group A patients were HLA A1-B8 (4 patients) and HLA A2-B40 (2 patients).

On the basis of the HLA typing, it should be pointed out that other participants presented at least one of the class I specificities composing these haplotypes (HLA-A1-B8, -A2-B40 and -A9-B12), as shown in table 1.

At initial examination, the cup-to-disc ratio ranged from 0.2 to 0.9, with a median of 0.4, for Group A and from 0.4 to 1.0, with a median of 0.85 , for Group B. At the current examination, the values ranged from 0.5 to 0.7, with a median of 0.8, for Group A and from 0.7 to 1.0 , with a median of 0.85 , for Group B.

No significant differences in cup-to-disc ratio were detected between the two groups at either time of evaluation (Group A x Group $B$ in the first examination: $p=0.8500$; Group A x Group B last examination: $p=0.2994)$. However, when the variation in the cup-to-disc ratio of group A patients was compared to that of Group B patients, significant differences were detected both when Group A was compared to Group B patients as a whole $(p=0.012)$ and when comparisons were made between different age ranges, as shown in table 2 .

When visual fields were compared between groups and between times, the variation was 1 to 3 (median: 2) for Group A and also for Group B (median: 1), with the difference being nonsignificant ( $p=0.61879)$. In other words, there was a significant anatomical loss, but not a significant physiological loss.

Regarding optical coherence tomography, the cup ranged from 0.6 to 0.98 (median: 0.85 ) in Group A and from 0.48 to 1.0 (median: 0.85 ) in Group B, with the difference being nonsignificant ( $p=0.55825$ ).

Nerve fiber layer losses ranged from 1 to 3 (median:1) in Group A and also ranged from 1 to 3 (median: 2) in Group B, with the difference being nonsignificant ( $p=0.26948)$.

\section{DISCUSSION}

The present study is the continuation of previous investigations which corroborated the involvement of the major histocompatibility complex in the development of different types of glaucoma, important cause of unavoidable blindness in Brazil ${ }^{(11-14)}$.

Torres et al., only studied Caucasian patients, whereas in the present study, were included patients with different ethnicities ${ }^{(9)}$.

Table 1. Absolute numbers of the HLA-A and HLA-B specificities that are part of the haplotypes associated with POAG in patients with glaucoma and associated class I haplotypes (Group A: $n=6$ individuals, 12 specificities), with glaucoma without the presence of the haplotypes associated with the condition (Group B: $n=19$ individuals, 38 specificities), and in control individuals (Group C: $n=257$ individuals, with only the subtypes presented by the subjects of the current study being listed)

\begin{tabular}{|c|c|c|c|c|c|c|}
\hline \multirow[b]{2}{*}{ Alleles } & \multicolumn{3}{|c|}{ Groups } & \multicolumn{3}{|c|}{ p value and OR } \\
\hline & A & B & $\bar{C}$ & $A \times B$ & $A \times C$ & $B \times C$ \\
\hline HLA-A1 & 4 & 1 & 50 & $\begin{array}{c}0.00925 \\
O R=18.50\end{array}$ & $\begin{array}{c}0.0263 \\
\mathrm{OR}=4.84\end{array}$ & 0.239 \\
\hline HLA-A2 & 3 & 9 & 128 & 1.0 & 1.0 & 0.978 \\
\hline HLA- A9 & 1 & 7 & 17 & 0.660 & 0.3444 & $\begin{array}{c}0.0006 \\
O R=6.60\end{array}$ \\
\hline HLA-B8 & 4 & 0 & 29 & $\begin{array}{c}0.0014 \\
\text { OR indefined }\end{array}$ & $\begin{array}{c}0.0044 \\
\mathrm{OR}=8.36\end{array}$ & 0.249 \\
\hline HLA-B12 & 0 & 4 & 62 & 0.560 & 0.376 & 1.0 \\
\hline HLA-B40 & 2 & 1 & 24 & 0.139 & 0.114 & 1.0 \\
\hline
\end{tabular}


Table 2. Comparison of the variations in the cup/disc ratio between Group A patients of different age ranges and group $B$ patients as a whole

\begin{tabular}{lc}
\hline A X B comparison & p value \\
\hline Older than 70 years & 0.0047 \\
Older than 60 years & 0.0409 \\
Older than 50 years & 0.0105 \\
Older than 40 years & 0.0170 \\
All patients & 0.0124 \\
\hline
\end{tabular}

One decade proved to be a long period for follow-up. During this period, many abandoned treatment or were lost to follow-up. Many were already elderly patients at the time of the first study, with some of them dying during the ten-year period. The aging of the population proved to be a difficulty since some patients presented reduced visual acuity, as well as hearing and locomotion difficulties (being always assisted by an accompanying person) and, at times, difficulties in understanding the examiner. Thus, the main limitation of the present study was sample size.

Another point to consider is that, as can be observed, the results regarding the cup-to-disc ratio differ from the results obtained by OCT, an exam that was not available at the time of first evaluation.

In the present study, the frequencies of the HLA-B12 antigen were similar in the three groups studied $(p=1.00)$, in contrast to the data reported by some authors ${ }^{(3-4)}$.

When the differences in the frequency of HLA subtypes were considered in the patients with the haplotypes pointed out by Torres et al. and in the patients with POAG without these haplotypes, as expected, the frequencies of the HLA-A1 and HLA-B8 subtypes were significantly higher $(p=0.0092$ and 0.0021 , respectively). In the comparison of Group A with the population controls, these two subtypes were also significantly different $(p=0.0263$ and 0.0077 , resspectively). The HLA-A9 antigen was more frequent among patients with glaucoma without the haplotypes associated with POAG than in the general population $(p=0.0003)^{(9)}$.

Although no significant differences in cup-to-disc ratio were detected between the two groups studied at the two times of assessment, the progression of anatomical damage (increased cup) was significantly greater $(p=0.0125)$ in Group A (patients with class I haplotypes associated with glaucoma) when compared to the total number of Group B patients. This difference was even greater $(p=0.0047)$ when Group B patients of the same age range as Group A patients (more than 70 years) were considered. This is the most important finding of the present study, which confirms literature data indicating an association between Major Histocompatibility Complex and POAG.

Despite the difference in anatomical damage to the head of the optic nerve, there was no significant difference between groups in the loss of retinal nerve fibers (evaluated by OCT, available only in the second phase of the study) or in the loss of visual field (evaluated by functional damage). However, the difference in the progression of the increase in optic nerve cup permits us to assume that the follow-up of the patients under study until they reach more advanced ages and the increase in sample size may point out haplotypes that may become genetic markers for POAG.

Once these haplotypes are defined, first-degree relatives of patients with glaucoma should have their HLA profile determined since the presence of one of the haplotypes represents an additional risk factor to be considered for the decision about the time when the clinical treatment of eventual ocular hypertension or of changes in the head of the optic nerve could be started.

\section{CONCLUSION}

There was greater progression of the anatomical changes of the optic nerve head attributable to glaucoma in patients with HLA haplotypes associated with predisposition to primary open-angle glaucoma, but no differences were detected between groups in the progression of physiological damage or in the loss of retinal nerve fibers. These results indicate that class I HLA haplotypes is associated with a faster progression of the changes in the optic nerve head in patients with glaucoma.

\section{ACNOWLEDGMENTS}

To Profa. Dra. Elza Araujo Torres and Maria Rosa Bet de Moraes Silva for the suggestions.

\section{REFERENCES}

1. Geiser DK, Wilensky JT. HLA antigens and acute angle-closure glaucoma. Am J Ophthalmol. 1979;88(2):232-5

2. Lecher R. Mechanisms of HLA and disease association. In: Lecher, Reditor. HLA and disease. London: Academic Press: 1994. p.83-91.

3. Shin DH, Becker B. The prognostic value of HLA-B12 and HLA-B7 antigens in patients with increased intraocular pressure. Am J Ophthalmol. 1976;82(6):871-4.

4. Rosenthal AR, Payne R. Association of HLA antigens and primary open-angle glaucoma. Am J Ophthalmol. 1979;88(3 Pt 1):479-82

5. Henley WL, Leopold IH, Aviner Z. Letter: Glaucoma and HLA antigens. Lancet. 1974; 2(7891):1273.

6. Gil-Carrasco FG, Granado J, Barojas-Weber, Gilbert-Lucido ME, Vargas-Alarcón G. Imunogenetic aspects in primary open-angle glaucoma in family members of mexican mesitzo glaucomatous patients. Am J Ophthalmol. 1994:118(6):744-8.

7. Ferreri G, D Andrea A, Castagna I, Rechichi C, Pettinato G, D'Andrea D. The hole of class I and class II HLA antigens primary open-angle glaucoma (POAG). Acta Ophthalmol Scand Suppl. 1998:(227):17-9.

8. Eren E, Traves P. The structure of major histocompatibility complex and its molecular interaction. In: Lechler R, Warrens A. HLA in healthy and disease. $2^{\text {nd }}$ ed. London: Academic Press; 2000. p.23-34

9. Torres EA, Silva MRBM, Bortolozzi J, Pellegino Júnior J, DeLima MG. Complexo HLA e glaucoma crônico simples. Rev Bras Alergia Imunopatol. 1989;12(6):198-201.

10. Keltner JL, Johnson CA, Cello KE, Edwards MA, Bandermann SE, Kass MA, Gordon MO; Ocular Hypertension Treatment Study Group. Classification of visual field abnormalities in the ocular hypertension treatment study. Arch Ophthalmol. 2003;121(5):643-50. Erratum in: Arch Ophthalmol. 2008;126(4):561.

11. Oliveira A, Paranhos Junior A, Prata Junior JA. Características dos pacientes atendidos pela primeira vez no Setor de Glaucoma da Universidade Federal de São Paulo - UNIFESP. Arq Bras Oftalmol. 2003;66(6):785-90.

12. Leske MC. Open-angle glaucoma - an epidemiologic overview. Ophthalmic Epidemiol. 2007:14(4):166-72

13. Foster A, Gilbert C, Johnson G. Changing patterns in global blindness: 1988-2008. Community Eye Health. 2008;21(67):37-9.

14. Cronemberg S, Lourenço LFS, Silva LC, Calixto N, Pires MC. Prognosis of glaucoma in relation to blindness at a university hospital. Arq Bras Oftalmol. 2009:72(2):199-204. 